\title{
Double Dislocation of Distal Interphalangeal (DIP) and Proximal Interphalangeal (PIP) Joints of the Little Finger
}

\section{Kenneth S. David-West}

Department of Orthopaedic Surgery, The Royal Hospital for Sick Children, UK

\section{Introduction}

Single interphalangeal joint dislocation of the hand is a common injury, but double interpahalangealjoints dislocation is very rare. The first reported case of double interphalangeal joint dislocation was in 1874 by Bartels [1]. Double dislocation of the distal interphalangeal and proximal interphalangeal joints, in same digit is common on the ulnar three digits [2]. with the little finger most commonly affected $[3,4]$.

Sprains and dislocations of the Interphalangeal Joint (IPJ) of the finger are relatively rare due to the protected position of this joint in the hand.

Most of the case reports in the literature are in young males sustaining such injuries while practicing throwing sports [4,5]. Our case report, however, is a double dislocation of the distal interphalangeal and proximal interphalangeal joints, following a fall.

\section{Case Report: Presentation}

A 28 year old healthy right handed female attended the Accident and Emergency department, with a hyperextension injury to her right little finger, following a fall on snow.

Her little finger was swollen, deformed (step ladder deformity) and very painful. Sensation was intact, perfusion was satisfactory and the skin was intact.

A radiograph later confirmed the provisional diagnosis of double dislocation of the distal and proximal interphalangeal joints (Figure 1).

Local anaesthesia in the form of a Metacarpal block with $1 \%$ lignocaine was performed and reduction was achieved by longitudinal traction. There was some laxity of the proximal interphalangeal joint .The finger was immobilised with a Zimmer finger split in the intrinsic plus position for three weeks. The patient was then referred to the occupational hand therapy department for hand exercises.

At six months the patient had achieved, full range of flexion and extension of the proximal interphalangeal joint ; full range of flexion of the distal interphalangeal joint, but extension of the distal interphalangeal joint was limited with a $15^{\circ}$ of extension lag.

\section{Discussion}

Double dislocation of the proximal and distal interphalangeal joints is a rare injury. The first published case was by Bartels in 1874 [1]. If the swelling is mild the 'step ladder deformity' will be obvious, but Vashista et al. [6] noted that swelling may obscure the clinical diagnosis, in which case radiological examination will be needed to establish the diagnosis. In our patient the step ladder deformity was obvious and the diagnosis confirmed with a radiograph.

In the literature there has only been one reported case of simultaneous triple dislocation (metacarpo-phangeal, proximal and distal interphalangeal joints) [6].

The little finger of the dominant hand is most frequently involved, followed by the ring finger $[3,4]$. The possible explanation is the lack of protection to the little finger, by the adjacent surrounding fingers, or due to weakness of supporting ligaments [7]. Another possible reason is that the bony anatomy of the finger itself leads to greater laxity on extension, with the shallow articular surface of the proximal phalanx resting on the spherical head of the distal phalanx [8].

The mechanism of injury is a hyperextension force on both joints, first occurring on the volar surface of the terminal phalanx, initially dislocating the distal interphalangeal joint and then dislocating the proximal interphalangeal joint in quick succession. Hence it is not a 'simultaneous' dislocation $[2,9,10]$.

The direct force on the fingertip results in a tear to the volar plate of both joints. This may be, with or without avulsion fractures of the distal insertions, hence allowing the bone to slide on the dorsum of the head of the proximal bone. The dislocation may be associated with rupture of the central slip of the extensor tendon [10].

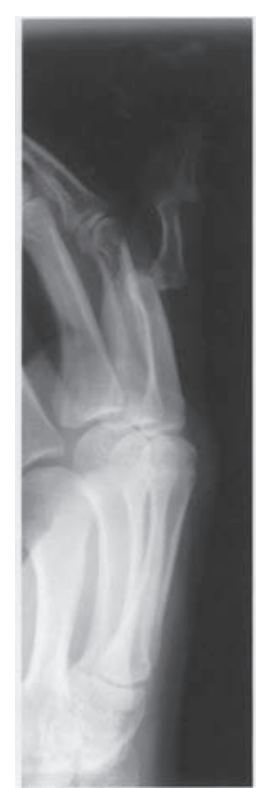

Figure 1: provisional diagnosis of double dislocation of the distal and proximal interphalangeal joints.

*Corresponding author: Department of Orthopaedic Surgery, The Royal Hospital for Sick Children, Yorkhill, Glasgow G3 8SJ, UK, E-mail: kd-west@ntlworld.com

Received February 27, 2013; Accepted April 18, 2013; Published April 20, 2013

Citation: David-West KS (2013) Double Dislocation of Distal Interphalangeal (DIP) and Proximal Interphalangeal (PIP) Joints of the Little Finger. J Trauma Treat 2 : 163. doi:10.4172/2167-1222.1000163

Copyright: ( 2013 David-West KS. This is an open-access article distributed under the terms of the Creative Commons Attribution License, which permits unrestricted use, distribution, and reproduction in any medium, provided the original author and source are credited. 
Citation: David-West KS (2013) Double Dislocation of Distal Interphalangeal (DIP) and Proximal Interphalangeal (PIP) Joints of the Little Finger. J Trauma Treat 2: 163. doi:10.4172/2167-1222.1000163

Page 2 of 2

Close reduction under local anaesthesia is the treatment of choice [2] if there is no soft tissue interposition. We were able to reduce our patient's dislocations by traction and manipulation.

Close reduction of the proximal interphalangeal joint could be difficult, if the condyle of the proximal phalanx buttonholes through the extensor aponeurosis, in volar dislocation.

After reduction; immobilisation in the functional position should be avoided, as it often leads to instability of the PIP joint [6]. The intrinsic plus position is the position of choice [10].

In summary, if this very rare injury is diagnosed early on, it can be treated by closed reduction under local anaesthesia,if there are not soft tissue injury, with three weeks of immobilization and physiotherapy, and a good functional outcome can be achieved.

\section{References}

1. Bartels M (1874) TraumatischeLuxationen. Arch KlinChir16: 636-654.

2. Bayne O, Chabot JM, Carr JP, Evans EF (1990) Simultaneous dorsal dislocation of interphalangeal joints in a finger. Clin Orthop Relat Res : 104-106.
3. Inoue G, Kino Y, Kondo K (1993) Simultaneous dorsal dislocation of both interphalangeal joints in a finger. Am J Sports Med 21: 323-325.

4. Curran AJ, McKiernan MV, McCann J (1993) Double interphalangeal joint dislocation in a little finger. Injury 24: 138.

5. Glickel SZ, Barron AO, EatonRG (1999) Dislocations and ligament injuries in the digits. In: Green DP, Hotchkiss RN, and Pederson WC, eds. Green's Operative Hand Surgery. (4thedn), NY: Churchill Livingstone, New York, USA.

6. Vashista GN, Krishnan KM, DeshmukhSC (2004) Simultaneous dislocations of the carpometacarpal and metacarpophalangeal joints of thethumb. Injury Extra 35: $56-8$.

7. Freitag P, Hurasuna SM, Milgram JW (1977) Double dislocationof the finger.A rare occurrence. Phys Sports Med 5: 83-84

8. Nathan FF, Schlein AP (1973) Multiple dislocations of a single finger. Hand 5 $52-54$.

9. Hindley CJ (1989) Triple dislocations in the index finger. J Trauma 29: 122-124.

10. Ikpeme JO (1977) Dislocation of both interphalangeal joints of one finger. Injury 9: 68-70. 